\title{
DISCUSSION
}

\section{PERSONAL BRANDING AS AN EXPATRIATE IN AUSTRIA}

The effect of living and working abroad can be a disorientating culture shock for many expatriates. Even moving between European countries where the geographic distance is relatively small, the sense of cultural dissonance can still be great. Furthermore, expatriates can often feel ambivalent about both their host country as well as their home nation, comparing the two endlessly and not feeling totally at home in either. Since moving to Austria from the UK in 2007, I have had time to reflect on the process of repositioning myself within the Central European business context and how this has challenged my perceptions of self-identity. In this short article, I will outline why I believe that it is instrumental that expatriates think of themselves as a brand.

Moving abroad creates an opportunity to build a new personal identity and brand. On arrival in a foreign country one often goes into survival mode during the initial weeks and months. Once this first "storming phase" has passed, the new reality becomes normalised and one has time to contemplate the nature of one's personal brand. Occasionally, one may even be able to exploit the "outsider" status to transcend unwritten social rules and class barriers, as foreigners are often given more social latitude. However, this can go both ways as a "foreigner" is not always perceived positively. Indeed, as I have experienced here in Austria, the narrow "valley mentality" has shaped an inherent suspicion of foreigners and doubtful questions why they have left their homeland. For expatriates relocating with a global firm, the cultural adjustment and brand building can be smoother, with practical infrastructure in place and the employee being part of a wider corporate culture. (However, even here, the employee must build a brand which enables personal and professional differentiation). For independent consultants, entrepreneurs and those in professional services, personal branding takes on a special significance in order to capture a share of voice in the crowded and typically indifferent marketplace.
Personal branding is nothing more than influencing the perceptions of one's target market, i.e. what stakeholders know and think about you and ensuring that you are "top of mind" in your given field. It is not to be confused with personal image, (what clothes you wear, where you holiday, who your friends are - your lifestyle), though certainly, one feeds into another. Personal branding has three components and can be answered by the following questions:

- Who are you?

- What do you do?

- What makes you unique and what value do you bring? (Your unique selling point).

The answers to these questions can help form a kind of "personal branding statement", which can provide one with clarity of vision and purpose when living in a foreign country can be disorientating and complex. Emotional appeal and "soft factors" are very important when considering a personal brand - ultimately, people buy from other people. International development coach, Rhyanna Watson believes that emotional intelligence and leadership style are yardsticks against which we may measure ourselves. "Firstly you have to have high emotional intelligence. Emotional intelligence (EI) is the ability to understand and manage both your own emotions, and those of the people around you. People with a high degree of emotional intelligence usually know what they're feeling, what this means, and how their emotions can affect other people. For leaders, having emotional intelligence is essential for success. After all, who is more likely to succeed - a leader who shouts at his team when he's under stress, or a leader who stays in control, and calmly assesses the situation?" Whilst there is no single path to success and "no one right way to create the brand called You", Rhyanna stresses the importance of being an "exceptional expert at something that has real value to yourself and others". Thirdly, 
“...you've got to be a broad-gauged visionary -- a leader, a teacher, a farsighted "imagineer." Fourthly, you've got to be passionate -- you've got to love and be obsessed with pragmatic outcomes. It's this simple: You are in charge of your brand. Except this: Start today as if not now, never".

On contemplation of personal brands such as Madonna, James Bond, Dalai Lama and Kate Moss, one finds them so compelling because they all provide "a singular unique vision" of what they represent. Arguably, they have all moved beyond the realms of being merely "advocates" or "influencers" as they all have achieved iconic status. Hence, we, as consumers, know what they stand for. Whilst most of us might not become icons in our fields, we can be the "go-to" person or thought-leader if we take time to determine our leading attribute, set goals for what we want to accomplish and identify ourselves with achieving one single powerful idea. Furthermore, as part of their brand image each of these icons encapsulates key elements of their national identity, for example, Madonna as the spirit of American reinvention, self-creation and free enterprise or James Bond as the quintessential British gentleman. As expatriates, one can learn from this and, as appropriate, subtly incorporate positive aspects of our national identity to create mystique in our personal brand.

Whilst this all may sound a bit calculated and premeditated, I would temper this by saying that a personal brand should not be a kind of artificial projection of a fantasy self, rather a reflection of one's inner values and true spirit. For example, in the popular TV show, "The Apprentice", we are familiar with how the contestants aggressively vie against the competitors to differentiate their professional and personal qualities. It is interesting to watch the unravelling of these personalities and the effect which they have on us as viewers. More often than not, we are drawn to the candidates who are natural and not aggressive in their approach, (remember no-one likes to be "sold" to). Building trust and authenticity as part of one's brand as an expatriate is important as rarely do people know, or care, where you have come from and what you have done. Lacking these reference points, they only have you as you are now to go on. Therefore, following through on promises and favours is very important and will help to build this trust.

Clearly there are a lot of national differences and specifics when doing business in CEE - even within a small country such as Austria there are great disparities between regional mentalities and business practices. Upon moving to the region, it is useful to spend time immersing oneself in the local business, national and local culture to develop an understanding of the value system and how this impacts your modus operandi. For example, I have found a number of key signposts to be important in understanding expatriate life and understanding one's business environment.

For example:

\section{Understanding of the concept of time}

Each country has its own concept of time, for example, London time or New York time are different, (those moving to New York from London find things a lot faster); Vienna time is slower still. This reflects a difference in capitalistic structures but also a value system which advocates time over money and living a balanced social and family life. This can mean that you may have to wait longer to receive your deliverable and adjust your expectations accordingly, as exerting pressure seems to have the opposite result of the desired effect.

\section{Respect, e.g. formality}

Language shapes our attitudes towards formality, with the German "Sie" creating a natural distance and authority between colleagues. This formality can extend to the correct use of academic titles, (very important in German-speaking countries), appropriate business attire, punctuality and refraining from asking any intrusive personal questions.

\section{Gender roles and expectations}

This is a subject unto itself and each person needs to decide what their own personal aspirations and boundaries are on the subject of gender equality. However, it is worth taking a "rain check" of prevailing gender attitudes in the working environment, if only to see what challenges and expectations one might face.

\section{How to say no}

Just as every culture understands time differently, each culture has a different way of saying "no". Whilst some South East Asian countries are infamous for their reluctance to disappoint expectations and say "no" outright, in Germany the Teutonic directness is the polar opposite. In Austria, a high value is place on personal charm and gallantry, (perhaps a legacy from courtly forms in imperial times), there is often a deferral to say "no", which is then manifested in lack of delivery or unfulfilled promises. By the same token, decide what your own boundaries and limits of acceptable behaviour are as surely some people may attempt to exploit the assumed naivety of a new kid on the block. 


\section{Working practices \& national culture}

Within a country the culture can be extremely localised and alliances fiercely regional. Whilst it may only be good manners to learn the local language or dialect and take an interest in the national culture, business relations and mutual understanding can often be eased by a genuine enthusiasm and knowledge of the local scene whether it is political, traditional or gastronomic.

\section{And finally}

Accept and embrace the local culture - it would be rude to do otherwise, after all, you are a guest in a foreign land. Take inspiration from the new input which surrounds you - a new way of looking at the world and take the opportunity to develop yourself further as an individual. It is an engine for growth. Above all, be tolerant and patient of others and yourself as building a brand takes time. It takes a while to normalise a new environment and nurture high performance.

Once one has a clearer picture of one's personal brand and where one is heading, the importance of building a wide network cannot be overstated. Whilst Social Media hardly needs any introduction, there may be some mileage in connecting with expatriate specific platforms such as Best of All Worlds, InterNations and a Small World. Real value comes from a genuine interest in real, live people met in a face-to-face setting. So often, when I hear the word "networking", I groan inwardly, thinking of pushy "Apprentice" or car salesmen types. Try and create a "pull" effect towards you. So in this spirit, think of what you can give not receive and it will surely come back to you one day - maybe not from the same person or the person whom you anticipated, but you will find your own personal brand of magic will work in remarkable ways.
Author

Joanna Park-Tonks

Public Relations Expert

Vienna, Austria

joanna@joannaparktonks.com 